\title{
Obama calls on other nations to step up their efforts to end Ebola outbreak
}

\author{
Michael McCarthy
}

Seattle

The US president, Barack Obama, has called on other countries to do more to combat the Ebola virus outbreak in west Africa. The outbreak, which was first reported last March, has now claimed at least 3400 lives, the World Health Organization has said.

"I'll be very honest with you-although we have seen great interest on the part of the international community, we have not seen other countries step up as aggressively as they need to," Obama said on Monday 6 October. If other countries think that they can "sit on the sidelines and just let the United States do it," the result will be "a less effective response, a less speedy response, and that means that people die," he said. Obama made his comments after receiving a briefing on the outbreak from health officials at the White House.

The president also commented on the case of Thomas Eric Duncan, a Liberian national who travelled to Dallas, Texas, and fell ill with Ebola shortly after his arrival. When he first sought medical care Duncan was initially sent home, even though he had told the hospital's emergency department staff that he had recently been in west Africa. The staff's failure to admit him at that time has raised questions about the US healthcare system's readiness to deal with imported cases. But health officials had "learned some lessons" from the case in Dallas, Obama said. "We don't have a lot of margin for error. The procedures and protocols that are put in place must be followed."

He added that US health officials would be working with state and local health workers to make sure that everyone- - "whether it's a hospital admissions desk, whether it is the doctors, the nurses, public health officials"-is aware of and follows the protocols needed to identify and isolate infected people. "We know what has to be done and we've got the medical infrastructure to do it. But this is an extraordinarily virulent disease when you don't follow the protocols," he said.

Duncan, who is in a critical but stable condition, was last weekend started on an experimental drug, brincidofovir, said officials at Texas Health Presbyterian Hospital in Dallas, where he is being treated in an isolation unit. Brincidofovir is an oral nucleotide analog that has been shown to have broad spectrum activity in vitro against a variety of DNA viruses, including the herpes virus family and adenovirus.

Testing at the US Centers for Disease Control and Prevention's Viral Special Pathogens Branch and the National Institutes of Health has shown that the drug also has in vitro activity against Ebola - a negative sense, single stranded RNA virus - said a spokesman for the drug's manufacturer, Chimerix, a biopharmaceutical company based in Durham, North Carolina. The drug has reached phase III trials for the treatment of cytomegalovirus and adenovirus infections, and information on the drug's safety and dosing can be applied to a trial for the treatment of Ebola infection, said Chimerix.

Despite some sensational news coverage and calls by a few politicians for flights from Africa to the US to be halted, most US residents have expressed confidence that the federal government will be able to control the spread of the disease. In a national survey by the Pew Research Center, 20\% of 1007 adults had a "great deal of confidence" in the federal government's ability to prevent a major outbreak, $38 \%$ had a "fair amount" of confidence, $24 \%$ had "not too much confidence," and $17 \%$ had "no confidence at all." Just $11 \%$ of those surveyed said that they were "very worried" that they would be exposed to the virus.

Texas health authorities are currently monitoring 48 people for signs of Ebola infection; 10 of the 48 are known to have been in contact with Duncan, and the remaining 38 are considered to be possible contacts. But none of those contacts has shown signs of illness, officials reported.

Cite this as: BMJ 2014;349:g6094

๑ BMJ Publishing Group Ltd 2014 